\title{
Syntaxin-4 mediates exocytosis of pre-docked and newcomer insulin granules underlying biphasic glucose-stimulated insulin secretion in human pancreatic beta cells
}

\author{
Li Xie • Dan Zhu • Subhankar Dolai • Tao Liang • \\ Tairan Qin • Youhou Kang • Huanli Xie • Ya-Chi Huang • \\ Herbert Y. Gaisano
}

Received: 12 August 2014 / Accepted: 3 February 2015 /Published online: 13 March 2015

(C) Springer-Verlag Berlin Heidelberg 2015

\begin{abstract}
Aims/hypothesis Of the four exocytotic syntaxins (Syns), much is now known about the role of Syn-1A (pre-docked secretory granules [SGs]) and Syn-3 (newcomer SGs) in insulin exocytosis. Some work was reported on Syn-4's role in biphasic glucose-stimulated insulin secretion (GSIS), but its precise role in insulin SG exocytosis remains unclear. In this paper we examine this role in human beta cells.

Methods Endogenous function of Syn-4 in human islets was assessed by knocking down its expression with lentiviral single hairpin RNA (lenti-shRNA)-RFP. Biphasic GSIS was determined by islet perifusion assay. Single-cell analysis of exocytosis of red fluorescent protein (RFP)-positive beta cells (exhibiting near-total depletion of Syn-4) was by patch clamp capacitance measurements $(\mathrm{Cm})$ and total internal reflection fluorescence microscopy (TIRFM), the latter to further assess single SG behaviour. Co-immunoprecipitations were conducted on INS-1 cells to assess exocytotic complexes.

Results Syn-4 knockdown (KD) of $77 \%$ in human islets caused a concomitant reduction in cognate Munc18c expression $(46 \%)$ without affecting expression of other exocytotic proteins; this resulted in reduction of GSIS in the first phase
\end{abstract}

Li Xie, Dan Zhu, Subhankar Dolai and Tao Liang contributed equally to this paper.

Electronic supplementary material The online version of this article (doi:10.1007/s00125-015-3545-4) contains peer-reviewed but unedited supplementary material, which is available to authorised users.

L. Xie $\cdot$ D. Zhu $\cdot$ S. Dolai $\cdot$ T. Liang $\cdot$ T. Qin $\cdot$ Y. Kang $\cdot$ H. Xie $\cdot$

Y.-C. Huang $\cdot$ H. Y. Gaisano $(\bowtie)$

Department of Medicine, Faculty of Medicine, University of

Toronto, Medical Sciences Building, 1 King's College Circle,

Toronto, ON, Canada M5S 1A8

e-mail: herbert.gaisano@utoronto.ca (by $42 \%$ ) and the second phase (by $40 \%$ ). Cm of RFP-tagged Syn-4-KD beta cells showed severe inhibition in the readily releasable pool (by 71\%) and mobilisation from reserve pools (by 63\%). TIRFM showed that Syn-4-KD-induced inhibition of first-phase GSIS was attributed to reduction in exocytosis of both pre-docked and newcomer SGs (which undergo minimal residence or docking time at the plasma membrane before fusion). Second-phase inhibition was attributed to reduction in newcomer SGs. Stx-4 co-immunoprecipitated Munc18c, VAMP2 and VAMP8, suggesting that these exocytotic complexes may be involved in exocytosis of pre-docked and newcomer SGs.

Conclusions/interpretation Syn-4 is involved in distinct molecular machineries that influence exocytosis of both predocked and newcomer SGs in a manner functionally redundant to Syn-1A and Syn-3, respectively; this underlies Syn-4's role in mediating portions of first-phase and second-phase GSIS.

Keywords Exocytosis $\cdot$ Human islets $\cdot$ Newcomer insulin granules $\cdot$ Syntaxin-4

$\begin{array}{ll}\text { Abbreviations } \\ \text { Cm } & \text { Capacitance measurements } \\ \text { EGFP } & \text { Enhanced green fluorescent protein } \\ \text { GLP-1 } & \text { Glucagon-like peptide-1 } \\ \text { GSIS } & \text { Glucose-stimulated insulin secretion } \\ \text { IP } & \text { Immunoprecipitation } \\ \text { KD } & \text { Knock down } \\ \text { NPY } & \text { Neuropeptide Y } \\ \text { PM } & \text { Plasma membrane } \\ \text { RFP } & \text { Red fluorescent protein } \\ \text { RRP } & \text { Readily releasable pool }\end{array}$




\begin{tabular}{|c|c|}
\hline SG & Secretory insulin-containing granule \\
\hline shRNA & Single hairpin RNA \\
\hline SM & Sec1/Munc18-like \\
\hline SNAP25/23 & $\begin{array}{l}\text { Synaptosomal-associated protein of } 25 / 23 \\
\mathrm{kDa}\end{array}$ \\
\hline SNARE & $\begin{array}{l}\text { Soluble } N \text {-ethylmaleimide-sensitive factor } \\
\text { attachment protein receptor }\end{array}$ \\
\hline Syn & Syntaxin \\
\hline t- & Target- \\
\hline TIRFM & $\begin{array}{l}\text { Total internal reflection fluorescence } \\
\text { microscopy }\end{array}$ \\
\hline $\mathrm{v}-$ & Vesicle- \\
\hline VAMP & Vesicle-associated membrane protein \\
\hline
\end{tabular}

\section{Introduction}

The membrane fusion machinery requires two key components: soluble $N$-ethylmaleimide-sensitive factor attachment protein receptor (SNARE) and Sec1/Munc18-like (SM) proteins $[1,2]$. The SNARE hypothesis paradigm dictates that cognate vesicle-(v-) SNAREs (vesicle-associated membrane proteins [VAMPs]) and target (t-) membrane SNAREs (syntaxins [Syn] and synaptosome-associated protein of $25 \mathrm{kDa}$ or $23 \mathrm{kDa}$ [SNAP25 or SNAP23]) assemble into complexes that mediate different exocytotic fusion events. During secretory insulin-containing granule (SG) priming, SM protein acts as a clasp that holds onto t-SNAREs (induces Syn into 'open' conformation) on plasma membrane (PM) and vSNARE on SGs, thus forming a quaternary complex in a partially zippered structure, bringing the SGs in close proximity with PM into a pre-docked state. In beta cells, combinatorial matching of $\mathrm{v}$ - and t-SNARE isoforms provides the molecular basis of distinct exocytotic events underlying the two phases of glucose-stimulated insulin secretion (GSIS). In addition to docked SGs, which are purported to form the readily releasable pool (RRP) that accounts for first-phase insulin release, large numbers of SGs, designated 'newcomer SGs', are recruited from the cell interior to contribute not only to second-phase release but also to first-phase release [3-5]. Insulin exocytosis also involves a small amount of compound exocytosis of SGs that can be greatly potentiated by cAMPacting glucagon-like peptide-1 (GLP-1) [6] or $\mathrm{Ca}^{2+}$-acting carbachol [7].

Of the four syntaxins mediating exocytosis, Syn-1, Syn-2 and Syn- 4 are found on beta cell PM, whereas Syn-3 is more abundant in SGs [8]. Pancreatic islets from Syn-1A (also known as Stxla) knockout mice exhibited blunted firstphase secretion, which was attributed to loss of ability of previously docked insulin SGs to undergo exocytosis, without perturbation of recruitment and fusion of newcomer SGs, as shown by total internal reflection fluorescence microscopy (TIRFM) of single beta cells [9]. Endogenous Syn-3 depletion by RNA interference inhibited GSIS by impairing recruitment and fusion of newcomer SGs in first and second phases without affecting pre-docked SGs [10]. Conversely, Syn-3 overexpression enhanced biphasic GSIS by increasing exocytosis of newcomer SGs. Previous work from D. Thurmond's laboratory (Indiana University, Indianapolis, IN, USA) focused on Syn-4's role in biphasic GSIS. Syn-4 (Stx4a) heterozygous global knockout mice exhibited impaired biphasic GSIS and insulin resistance [11, 12]. Syn-4 depletion also caused reduction in cognate Munc18c levels in islets [11]. Conversely, Syn-4 overexpression in transgenic mice showed parallel upregulation of endogenous Munc18c, along with increased GSIS and insulin sensitivity $[11,13,14]$. In their most recent study, Syn-4 overexpression was found to increase the efficiency of insulin release in the islets of humans with and without type 2 diabetes mellitus [15]. However, Syn-4's precise role in insulin SG exocytosis has not been shown. While Syn-4's actions in first-phase GSIS suggest a role in exocytosis of pre-docked SGs, its effects on second-phase secretion suggests that Syn-4 might also have a role in recruitment and exocytosis of newcomer SGs [5].

Here, we found that depletion of endogenous Syn-4 employing lenti-shRNA-RFP in human islets inhibited GSIS in first and second phases. Patch clamp capacitance measurements $(\mathrm{Cm})$ showed severe inhibition in the RRP and SG mobilisation from reserve pools. TIRFM illustrated that Syn4-knockdown (KD) inhibition of first-phase GSIS was attributed to reduction in exocytosis of both pre-docked and newcomer SGs and second-phase inhibition was attributed to reduction in exocytosis of newcomer SGs. Thus, Syn-4 regulation of exocytosis of both pre-docked and newcomer SGs is reminiscent of and functionally redundant to Syn-1A [9] and Syn-3 [10], respectively.

\section{Methods}

Cell culture and lentivirus transduction Human islets from institutional review board-approved healthy donors (written informed consent from donors or next of kin) were isolated and provided by IsletCore (P. MacDonald, University of Alberta, Edmonton, AB, Canada). Islet use was approved by the Institutional Review Board at University of Toronto. Islets were dispersed into single cells as described in electronic supplemental material (ESM) Methods. Control (lenti-controlRFP; scrambled single hairpin RNA [shRNA]-RFP) and Syn-4-shRNA-RFP lentivirus (lenti-Syn-4-shRNA-RFP; shRNA sequence: GCAGTCCGAATACCGAGAGAA) from GenTarget (San Diego, CA, USA) were used to transduce human islets or single cells. Cellular entry of viral particles was confirmed by red fluorescent protein (RFP) expression 
observed by epiflourescence imaging when performing patch clamp and TIRF imaging studies.

Western blotting Western blots of pancreatic islets and indicated tissues were performed with primary antibodies obtained from commercial sources (see ESM Methods) or that were gifts, including Munc18c (from D. Thurmond, Indiana University) and VAMP8 (from W. Hong, Institute of Molecular and Cell Biology, Proteos, Singapore). All of the antibodies used in the current work have been validated and used in similar experiments $[16,17]$.

Confocal immunofluorescence microscopy Samples (human islets, human single beta cells and C57BL/6 mouse beta cells) were fixed and immunostained as described in ESM Methods. Images were examined using a Leica DMIRE2 inverted fluorescence microscope (Leica Microsystems, Wetzlar, Germany) laser scanning confocal imaging system equipped with a spinning disc confocal scan head.

Islet perifusion Human islets infected with lenti-control-RFP and lenti-Syn-4-hRNA-RFP for $48 \mathrm{~h}$ were subjected to perifusion assays as previously reported [10]. Results are presented as insulin secretion normalised to total islet insulin content.

Electrophysiology Capacitance measurements were performed as we previously reported [18], and described in detail in the ESM Methods. Exocytotic events were elicited by a train of ten $500 \mathrm{~ms}$ depolarisation pulses from $-70 \mathrm{mV}$ to $0 \mathrm{mV}$. All recordings were performed at $30^{\circ} \mathrm{C}$.

TIRFM and data analysis TIRFM and analysis of data was performed with a Nikon TIRF microscope system (Nikon, Toronto, ON, Canada) as previously reported $[10,19]$ and described in detail in the ESM Methods. A monolayer of human beta cells was infected with adenovirus neuropeptide Y (NPY)-enhanced green fluorescent protein (EGFP) and cultured for 24-36 h before performing TIRFM. Fusion events, indicated by abrupt brightening of NPY-EGFP fluorescence, were manually selected and analysed as previously reported $[10,18,19]$.

Immunoprecipitation This was performed with INS-1 cells as previously reported $[16,17]$ and described in detail in ESM Methods. Cells intended for stimulation were pre-incubated for $30 \mathrm{~min}$ with $10 \mathrm{nmol} / 1 \mathrm{GLP}-1$ at $0.8 \mathrm{mmol} / 1$ glucose, then stimulated with $16.7 \mathrm{mmol} / 1$ glucose (containing GLP-1) for $30 \mathrm{~min}$. A $1 \mathrm{mg}$ protein extract of cell lysates was used for each condition. Immunoprecipitation (IP) was with $2 \mu \mathrm{g}$ Syn4 antibody (Synaptic Systems, Goettingen, Germany). IP experiments on HEK293 cells, transfected with Syn-4, VAMP2 or VAMP8, were similar to those carried out on INS-1 cells.
Statistical analysis Data are presented as mean \pm SEM. Statistical significance was evaluated by Student's $t$ test or MannWhitney rank sum test (SigmaStat 3.11; Systat Software, Chicago, IL, USA) and considered significant when $p<0.05$.

\section{Results}

Syn-4 is abundant in human islet beta cells and its expression is effectively reduced by lenti-shRNA Confocal microscopy imaging showed that Syn-4 is abundant in human beta cells but not alpha cells (Fig. 1a) and is localised to PM in both human and C57BL/6 mouse beta cells (Fig. 1b), the latter consistent with a previous report [11]. To assess the function of endogenous Syn-4, we employed shRNA lentivirus to deplete endogenous Syn- 4 protein. Western blots showed that lenti-shRNA-RFP treatment depleted endogenous Syn-4 levels by $77 \%$ in human islets (Fig. 1c, d). Of note, levels of cognate Munc18c were reduced by $46 \%$, whereas levels of Syn-3, SNAP23, SNAP25, VAMP2 and VAMP8 were not altered. The coordinate reduction in Munc18c with Syn-4 depletion is similar to previous findings in $S y n-4$ heterozygous $(-/+)$ knockout mice $[11,12]$. We performed triple labelling of lenti-Syn-4-shRNA-RFP, Syn-4-FITC and Insulin-Cy5 in whole human islets, using lenti-RFP with scrambled shRNA as control (Fig. 1e). Whereas control islets continued to show abundance of Syn-4 in beta cells across the islet (Fig. 1e), in lenti-Syn-4-shRNA-treated islets, only some residual Syn-4 was left in the islet core (Fig. 1e). This is more clearly seen when islets dispersed into single cells were infected; dispersed cells have higher infection efficiency than islets. Here, lentiSyn-4-shRNA-RFP infection depleted Syn-4 in the majority of human beta cells and only a small amount of residual Syn-4 (weak Syn-4 signal) was left in RFP-positive beta cells (Fig. 1f). Therefore, single RFP-positive beta cells exhibited near-total depletion of Syn-4 and were thus ideal for singlecell analysis of Syn-4 secretory function.

Syn-4 depletion in human islets reduced biphasic GSIS To examine the function of endogenous Syn-4 in biphasic GSIS, human islets were transduced with lenti-control-RFP or lentiSyn-4-shRNA-RFP and GSIS was assessed by islet perifusion assay. Basal insulin secretion in response to low glucose was similar. The biphasic secretory pattern in response to high glucose $(16.7 \mathrm{mmol} / \mathrm{l})$ was disrupted in Syn4-KD islets, with a blunted characteristic first-phase transient burst of insulin release and subsequent reduction in sustained second-phase release (Fig. 2a). AUC analysis showed that Syn- 4 depletion resulted in a $42 \%$ reduction (Syn-4-KD, $6.62 \pm 0.16$; control, $11.43 \pm 0.75 ; p<0.01$ ) in the first phase (10-25 $\mathrm{min}$ ), a $40 \%$ reduction (Syn-4-KD, $8 \pm 0.52$; control, $13.25 \pm 0.88 ; p<0.01)$ in the second phase $(27-45 \mathrm{~min})$ and a 


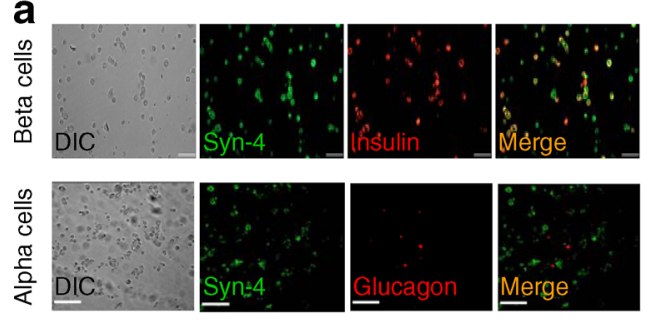

\section{b}
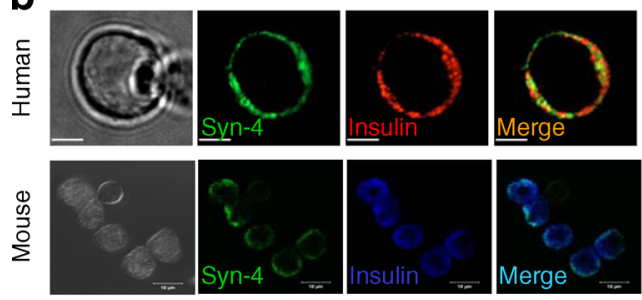

c
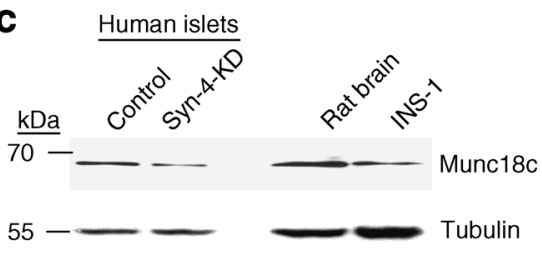

35

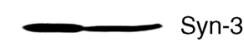

35
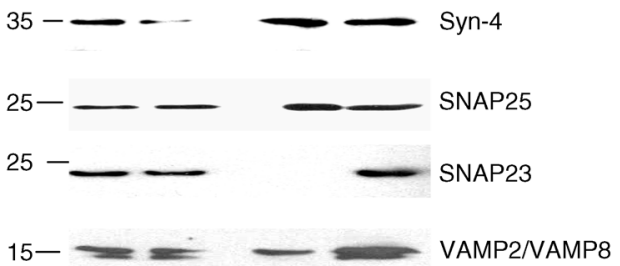

Fig. 1 Syn-4 is abundant in human islet beta cells and its expression reduced by lenti-shRNA. (a) Confocal images show that Syn-4 is abundant in human insulin-containing beta cells and less abundant in human glucagon-containing alpha cells. Scale bars, $50 \mu \mathrm{m}$. (b) Syn-4 is located in the PM of human (scale bars, $5 \mu \mathrm{m}$ ) and C57BL/6 mouse (scale bars, $10 \mu \mathrm{m}$ ) beta cells. (c) Western blotting analysis of lenti-Syn-4-shRNARFP-induced knockdown of Syn-4 expression in human islets. Representative blots of three separate experiments; means \pm SDs are shown in (d). White bars, control; grey bars, Syn- $4-\mathrm{KD}$. ${ }^{* *} p<0.01$ vs control. (e) Triple

$54 \%$ reduction (Syn-4-KD, 7.38 \pm 0.73 ; control, $16.05 \pm 2.09$; $p<0.05)$ in GLP-1 plus high-glucose-stimulated insulin secretion (46-65 min, Fig. 2b). Figure $2 \mathrm{c}$ shows that there was no difference in insulin content between control and Syn-4-KD islets. This result demonstrates that Syn-4 depletion in human islets reduced both first-phase and second-phase GSIS, suggesting that part of the first-phase and second-phase GSIS is governed by Syn-4-independent pathways.

Syn-4 depletion reduced depolarisation-induced exocytosis of SGs from RRP and reserve pool It was postulated that exocytosis of RRP and mobilisation from reserve pool correspond to first- and second-phase GSIS, respectively [20]. To examine

\section{d}
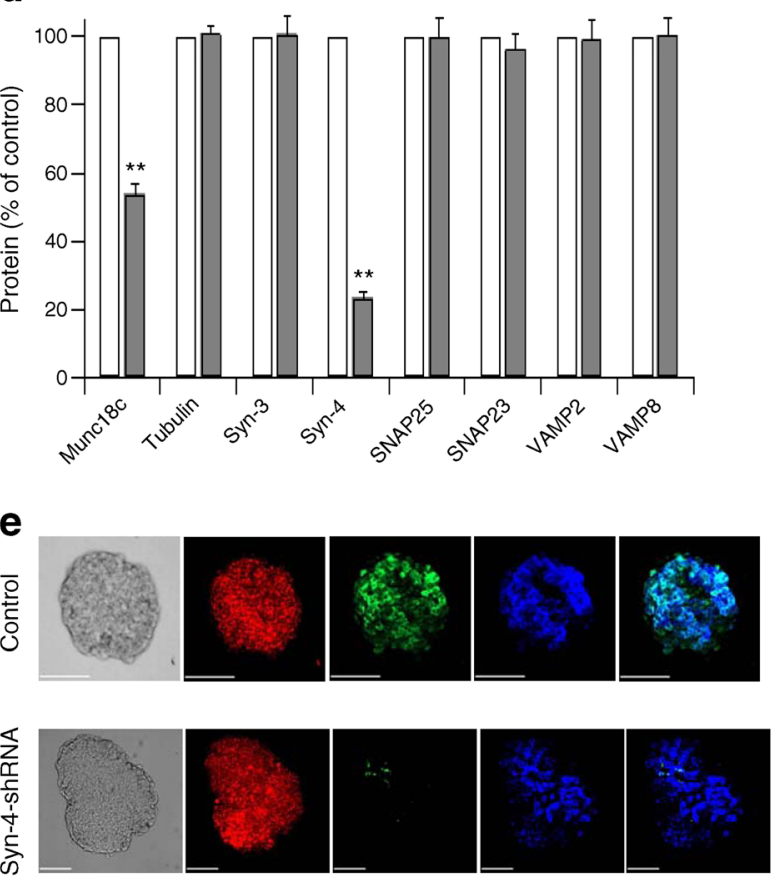

f

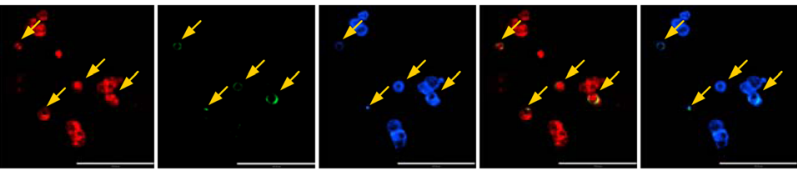

labelling of lenti-Syn-4-shRNA-RFP (red), Syn-4-FITC (green) and insulin-Cy5 (blue) in human islets showed that lenti-Syn-4-shRNA-RFP infection resulted in residual Syn-4 in the islet core, compared with control lenti-shRNA-RFP treatment, which showed abundant Syn-4 in beta cells. Scale bars, $100 \mu \mathrm{m}$. (f) Infection of dispersed islet cells with lentishRNA-RFP eliminated Syn-4 in most beta cells, with weak Syn-4 staining left in a few beta cells (arrows). Same triple labellings as (e). Scale bars, $100 \mu \mathrm{m}$; DIC, differential interference contrast

endogenous Syn-4 function in insulin SG pools and exocytotic kinetics, we performed patch clamp $\mathrm{Cm}$ using lenti-control/ RFP- and Syn-4-shRNA/RFP-expressing human beta cells. Insulin exocytosis was elicited by a train of ten $500 \mathrm{~ms}$ depolarisation pulses, with the first two pulses approximating the size of RRP of primed and fusion-ready SGs; subsequent pulses estimated the rate of SG refilling or mobilisation from reserve pool(s) to RRP, where SGs are subsequently primed for fusion competence [21]. Cm increase in Syn-4-KD cells was greatly inhibited at every depolarising pulse (Fig. 3a, b) compared with control cells, in which the size of the RRP was markedly reduced by $71 \%$ (Syn- $4-\mathrm{KD}, 3.36 \pm 0.77 \mathrm{fF} / \mathrm{pF}$; control, $11.52 \pm 2.52 \mathrm{fF} / \mathrm{pF} ; p<0.01$; Fig. $3 \mathrm{c})$, and the rate of $\mathrm{SG}$ 

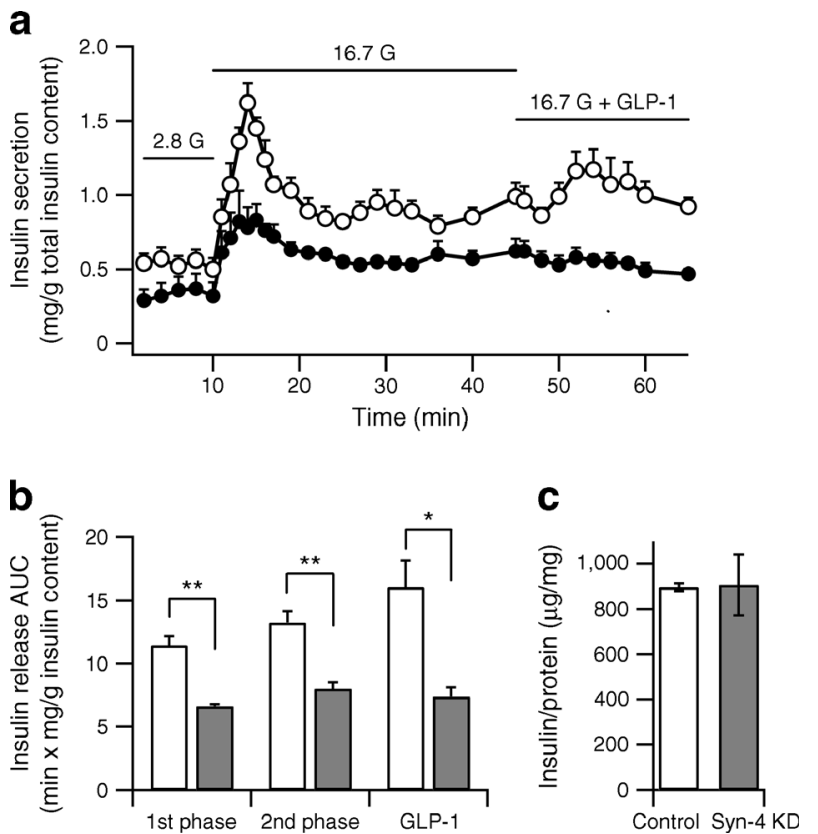

Fig. 2 Depletion of Syn-4 in human islets causes reduction in first-phase and second-phase GSIS and GLP-1-potentiated GSIS. (a) Human islets infected with lenti-Syn-4-shRNA-RFP (black circles) or lenti-control shRNA-RFP (control, white circles) were subjected to islet perifusion assays. $2.8 \mathrm{G}, 2.8 \mathrm{mmol} / 1$ glucose; $16.7 \mathrm{G}, 16.7 \mathrm{mmol} / 1$ glucose. (b) AUC analysis of first-phase (10-25 min) and second-phase (27$45 \mathrm{~min}$ ) GSIS and high glucose+GLP-1- (46-65 min) stimulated insulin secretion. Basal secretion was not significantly affected. ${ }^{*} p<0.05$ and ${ }^{* *} p<0.01$ vs control; $n=4$. White bars, control; grey bars, Syn-4-KD. (c) Bar chart showing islet insulin content (insulin/protein), $n=4$

refilling/mobilisation was severely reduced by $63 \%$ (Syn-4$\mathrm{KD}, 8.1 \pm 2.03 \mathrm{fF} / \mathrm{pF}$; control, $21.9 \pm 4.04 \mathrm{fF} / \mathrm{pF} ; p<0.01$;
Fig. 3c). This result suggests that Syn-4 depletion greatly impairs depolarisation-induced exocytosis by affecting the RRP and mobilisation of SGs from reserve pool(s). Beta cells were identified by their large size, measured electrophysiologically with an average $\mathrm{Cm}$ of $\sim 10 \mathrm{pF}$ as previously reported [22].

Syn-4 depletion causes reduction in exocytosis of previously docked SGs during high- $K^{+}$stimulation To enable visualisation of the spatio-temporal mobilisation of populations of SGs and single SG fusion dynamics, we employed time-lapse TIRFM to monitor exocytosis of SGs tagged with NPYEGFP. On stimulation single SG fusion events were observed as flashes of fluorescence, which rapidly dissipated in a cloudlike diffusion pattern. We verified that fluorescence dissipation was not due to photobleaching $[10,19]$. These exocytotic events were, however, not uniform and could be categorised into three distinct modes of exocytosis. 'Pre-dock' fusion mode refers to SGs that were already docked onto the PM for a period of time prior to stimulation (shown in black in Fig. 4a, b). 'Newcomer SGs' were new SGs appearing de novo under an evanescent field after stimulation and then underwent exocytosis, appearing in two distinct patterns as described previously [4, 10, 19, 23]: 'no-dock' newcomer SGs (shown in white in Fig. 4a, b) were newly recruited by stimulation and immediately fused with PM (docking state of $<200 \mathrm{~ms}$, the minimal interval between two consecutive frames); 'short-dock' newcomer SGs (shown in grey in Fig. 5a, b) were those newly recruited by stimulation, and first docked for some time, varying from seconds to minutes, at the PM, then fused with PM. Beta cells were identified by their large size and response to glucose.

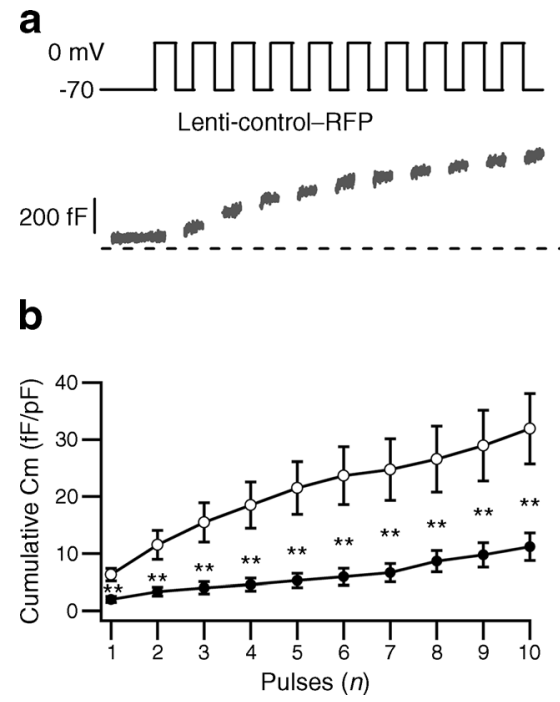

Fig. 3 Depletion of Syn-4 in human beta cells causes reduction in RRP and SG pool mobilisation. Patch clamp $\mathrm{Cm}$ were performed on single human beta cells (RFP-positive) infected with lenti-control shRNA-RFP or lenti-Syn-4-shRNA-RFP. (a) Representative recordings of exocytosis during a train of $500 \mathrm{~ms}$ depolarisations from -70 to $0 \mathrm{mV}$. (b) Cumulative changes in cell capacitance normalised to basal cell membrane
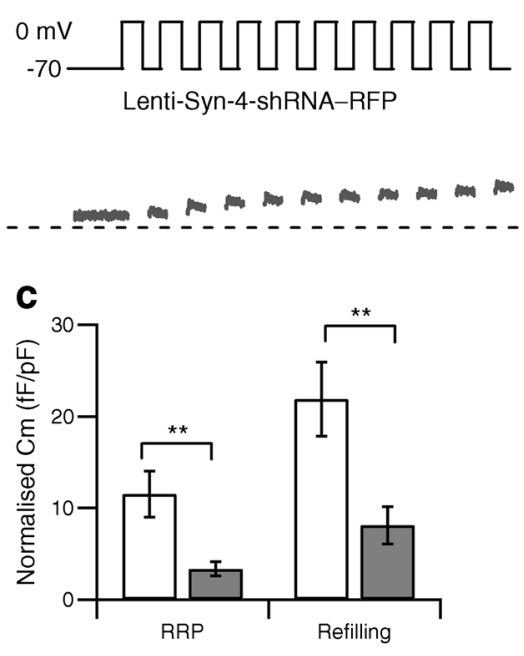

capacitance $(\mathrm{fF} / \mathrm{pF})$ in control (white circles, $n=10$ cells) and Syn-4-KD (black circles, $n=10$ cells) beta cells. (c) Size of RRP $\left(\Delta \mathrm{Cm}_{1 \mathrm{st}-2 \mathrm{nd}}\right.$ pulse) and rate of SG mobilisation $\left(\Delta \mathrm{Cm}_{3 \mathrm{rd}-10 \mathrm{th}}\right.$ pulse) $(n=8-10$ cells $)$. White bars, control; grey bars, Syn-4-KD. Values represent means \pm SDs. $* * p<0.01$ vs control 

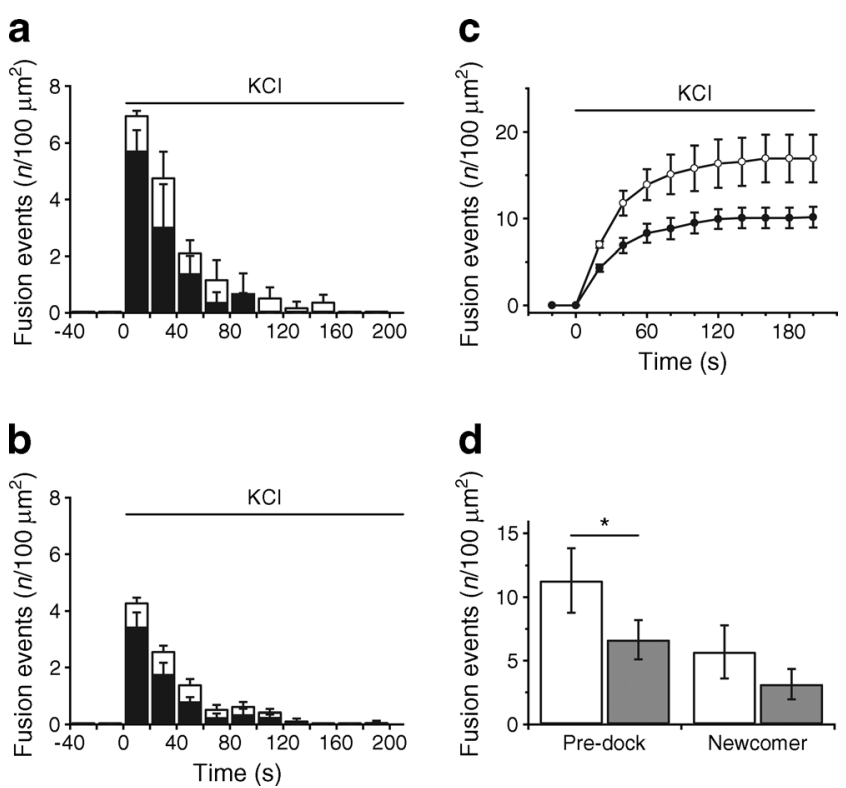

Fig. 4 Syn-4 depletion caused reduction in high- $\mathrm{K}^{+}$-evoked exocytosis of previously docked insulin SGs. (a, b) Insulin SG exocytosis dynamics evoked by $50 \mathrm{mmol} / 1 \mathrm{KCl}$ from control (a) and Syn-4-KD (b) human beta cells. Black bars, pre-docked SGs; white bars, newcomer SGs. Data are from ten cells for each group, expressed as means \pm SDs. (c) Normalised cumulative fusion events of SGs per unit area from control (white circles) and Syn-4-KD (black circles) beta cells. (d) Summary of fusion events from pre-docked and newcomer SGs in the first and second phase after $50 \mathrm{mmol} / \mathrm{l}$ glucose stimulation. White bars, control; grey bars, Syn-4-KD. Values represent means \pm SDs. ${ }^{*} p<0.05$ vs control
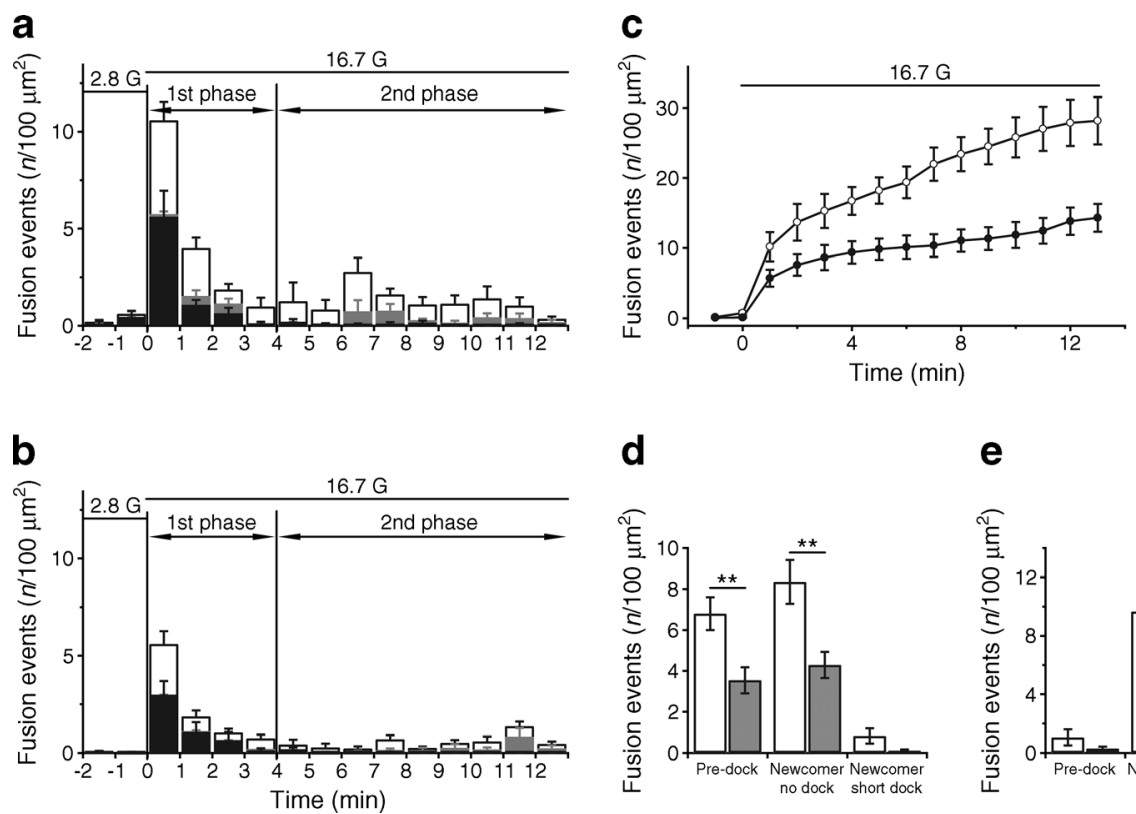

Fig. 5 Syn-4 depletion diminishes biphasic GSIS by reducing predocked and no-docked newcomer SG exocytosis. $(\mathbf{a}, \mathbf{b})$ Biphasic insulin SG exocytosis dynamics caused by $16.7 \mathrm{mmol} / \mathrm{l}$ glucose stimulation from human beta cells treated with lenti-control-RFP (a) and lenti-Syn-4shRNA-RFP (b). Histograms of fusion events in the first phase (first 4 min stimulation) and second phase (5-13 min). Black bars, pre-docked SGs; white bars, no-dock SGs; grey bars, short-dock newcomer SGs; $n=$ d

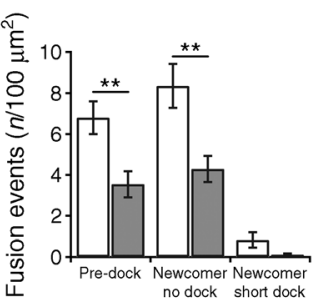
and $* * p<0.01$ vs control
Previously docked SGs are known to be preferentially released during high- $\mathrm{K}^{+}$stimulation [18, 20, 24], and this occurs mostly within the first few minutes. Consistently, $50 \mathrm{mmol} / \mathrm{l}$ $\mathrm{KCl}$ triggered exocytosis of mainly previously docked (predocked) SGs in the first few minutes from control and Syn-4$\mathrm{KD}$ cells (Fig. $4 \mathrm{a}, \mathrm{b}$ ). Here, there was a $41 \%$ reduction in exocytosis in the first $3 \mathrm{~min}$ (Fig. 4c), mostly accounted for by a reduction of exocytosis of pre-docked SGs in Syn-4-KD cells, compared with control cells (summary analysis in Fig. $4 d ; 6.65 \pm 1.55$ events $/ 100 \mu \mathrm{m}^{2}$ in Syn- $4-\mathrm{KD}$ cells vs $11.3 \pm 2.52$ events $/ 100 \mu \mathrm{m}^{2}$ in control cells). High- $\mathrm{K}^{+}$stimulation had less of an effect on newcomer SGs (Fig. 4a, b), at least less so than glucose stimulation (Fig. 5), and this was not significantly affected by Syn-4-KD (Fig. 4d). These results confirm that for $\mathrm{K}^{+}$-induced exocytosis, initial docking of insulin SGs on PM is required. More importantly, these results show that Syn-4 mediates exocytosis of previously docked SGs, which is consistent with the $\mathrm{Cm}$ experiments wherein the RRP of SGs is reduced in Syn-4-KD during depolarisation stimulation (Fig. 3). These results are consistent with the thinking of D. Thurmond's research group [11-14].

Syn-4 depletion diminishes biphasic GSIS by reducing exocytosis of pre-docked and newcomer $S G$ S We assessed the pattern(s) of fusion events affected by knockdown of Syn-4 with glucose stimulation. At $2.8 \mathrm{mmol} / \mathrm{l}$ glucose, there were few spontaneous fusion events of mainly pre-docked SGs e

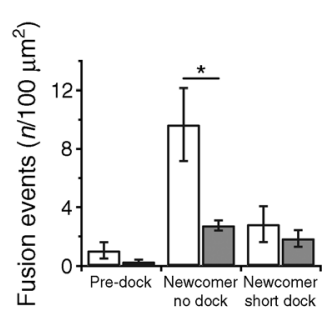

10 cells each, expressed as means \pm SDs. $2.8 \mathrm{G}, 2.8 \mathrm{mmol} / 1$ glucose; $16.7 \mathrm{G}, 16.7 \mathrm{mmol} / \mathrm{l}$ glucose. (c) Normalised cumulative fusion events of SGs per unit area from control (white circles) and Syn-4-KD (black circles) beta cells. (d, e) Summary of fusion events from pre-docked and newcomer SGs in first-phase (d) and second-phase (e) GSIS; ${ }^{*} p<0.05$ 
(Fig. 5a, b). Upon high-glucose stimulation $(16.7 \mathrm{mmol} / \mathrm{l})$ predocked and newcomers SGs make a similar contribution to first-phase GSIS, but newcomer SGs accounted for almost all of the second-phase GSIS. In first-phase GSIS, there was obvious inhibition of pre-docked (Fig. 5a, b; control $6.8 \pm 0.8$ vs Syn-4-KD $3.54 \pm 0.64$ events/100 $\left.\mu \mathrm{m}^{2}, p<0.01\right)$ and nodocked (Fig. 5a, b; control $8.35 \pm 1.07$ vs Syn-4-KD $4.29 \pm$ 0.64 events $/ 100 \mu \mathrm{m}^{2} ; p<0.01 ; n=10$ cells) newcomer SGs from Syn-4-KD cells (Fig. 5c, d). In second-phase GSIS, there was reduction only in no-docked newcomer SGs (Fig. 5c, e; control $9.66 \pm 2.49$ vs Syn-4-KD $2.75 \pm 0.35$ events $/ 100 \mu \mathrm{m}^{2}$; $p<0.05 ; n=10$ cells). With GLP-1 potentiation of highglucose stimulation all exocytotic events were amplified, including pre-docked and newcomer SGs in control and Syn-4KD cells (Fig. 6a-d), as we have reported before [6, 17, 19]. Syn-4 depletion greatly reduced fusion of pre-docked (control $9.36 \pm 1.65$ vs Syn-4-KD $5.82 \pm 1.34$ events $/ 100 \mu \mathrm{m}^{2} ; p<0.05$ ) and no-docked (control $32.9 \pm 3.3$ vs Syn- $4-K D$ 12.5 \pm 2.8 events $/ 100 \mathrm{\mu m}^{2} ; p<0.001 ; n=10$ cells) newcomer SGs (Fig. 6d). This result suggests that Syn-4 depletion inhibits biphasic GSIS by reducing both pre-docked and no-docked newcomer SGs, and that reduction of newcomer SGs underlies the reduction of second-phase GSIS by Syn-4-KD.

Munc18c-Syn-4 SNARE complexes bind SNAP25, SNAP23, VAMP2 and VAMP8 The molecular basis of the exocytotic
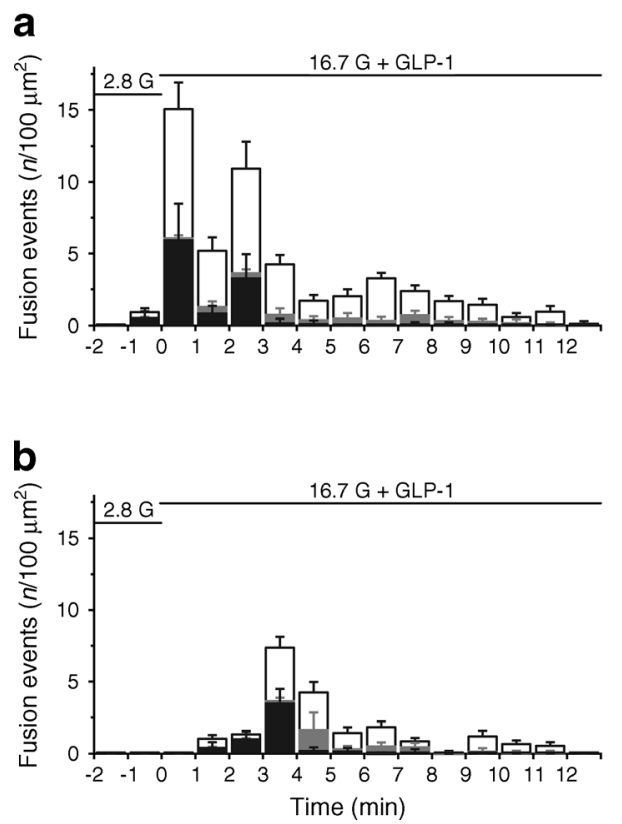

Fig. 6 Syn-4 depletion diminishes GLP-1-potentiated GSIS by reducing exocytosis of pre-docked and no-docked newcomer SGs. (a, b) Biphasic insulin granule exocytosis dynamics caused by $16.7 \mathrm{mmol} / 1$ glucose and $10 \mathrm{nmol} / 1$ GLP-1 from human beta cells treated with lenti-control-RFP (a) and lenti-Syn-4-shRNA-RFP (b). Black bars, pre-docked SGs; white bars, no-dock SGs; grey bars, short-dock newcomer SGs. Data were obtained from ten cells for each, and expressed as mean \pm SEM. (c) machinery formed by cognate Munc18c and Syn-4 in exocytosis of GLUT-4 vesicles in adipocytes and muscles has been well studied, but only to lesser extent in insulin SG exocytosis $[14,15]$. We previously reported that pancreatic acini employed Munc18c-Syn-4-VAMP8-SNAP23 as the putative SM-SNARE complex mediating basolateral exocytosis that causes pancreatitis [25-27]. We showed that all beta cell Syns displayed promiscuous binding to VAMP2 and VAMP8 and to SNAP25 and SNAP23, although each Syn has a preference for a particular VAMP $[16,17]$. To determine whether beta cell Syn-4-Munc18c complexes bind to VAMPs and SNAP25 isoform SNAP23, we performed immunoprecipitation experiments in INS-1 cells (Fig. 7a, b), since it would be prohibitive to use human islets for these studies as they require a high abundance of protein. INS-1 cells were kept in either a nonstimulatory condition $(0.8 \mathrm{mmol} / \mathrm{l}$ glucose $)$ or were maximally stimulated with $16.7 \mathrm{mmol} / \mathrm{l}$ glucose plus $10 \mathrm{nmol} / \mathrm{l} \mathrm{GLP}-1$. GLP-1 was included to reliably increase the abundance of SM-SNARE complex formation mediating these fusion events [17]. Figure 7c, d shows that Syn-4 co-precipitated SM-SNARE complexes that included Munc18c, SNAP25, SNAP23, VAMP2 and VAMP8; stimulation caused greater increases in SNAP25 (by 166\%), SNAP23 (by $80 \%$ ) and VAMP2 (by 142\%). Although VAMP8 co-precipitation was not significantly increased during stimulation, Syn-4 can nonetheless directly bind VAMP8 to a similar extent as
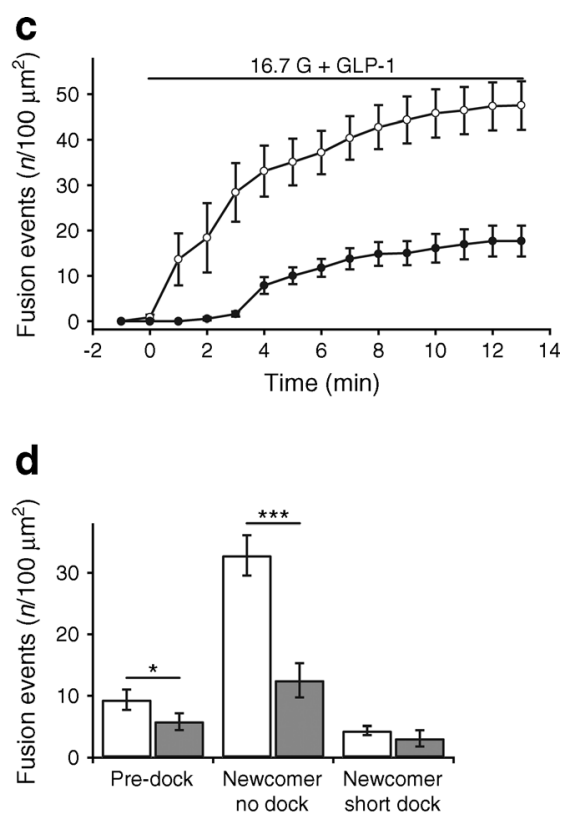

Normalised cumulative fusion events of insulin granules per unit area from control (white circles) and Syn-4-KD (black circles) human beta cells. (d) Summary of fusion events from pre-docked SGs and newcomer SGs after $16.7 \mathrm{mmol} / 1$ glucose and $10 \mathrm{nmol} / \mathrm{l} \mathrm{GLP}-1$ stimulation from control (white bars) and Syn-4-KD (grey bars) beta cells. Values represent the means \pm SDs. ${ }^{*} p<0.05$ and ${ }^{* * *} p<0.001$ vs control. $2.8 \mathrm{G}, 2.8 \mathrm{mmol} / 1$ glucose; $16.7 \mathrm{G}, 16.7 \mathrm{mmol} / \mathrm{l}$ glucose 
a

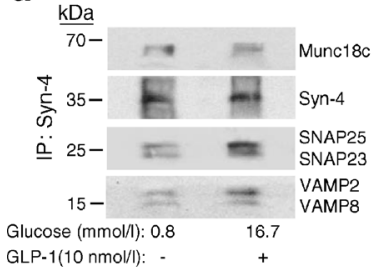

C
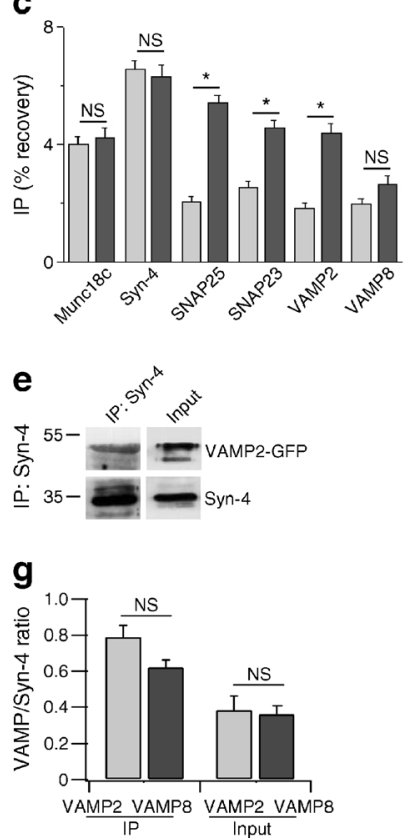

Fig. 7 Syn-4 co-immunoprecipitation of VAMP2 and VAMP8. (a, b) Upon stimulation of INS-1 cells, Syn-4 forms SM-SNARE complexes. INS-1 cells were in non-stimulatory condition $(0.8 \mathrm{mmol} / 1$ glucose $)$ or were stimulated with $16.7 \mathrm{mmol} / \mathrm{l}$ glucose $+10 \mathrm{nmol} / \mathrm{l} \mathrm{GLP}-1$. From each condition, $1 \mathrm{mg}$ of protein was subjected to immunoprecipitation (IP) with Syn-4 antibody and co-precipitated proteins were identified (a). 'Input' controls (50 $\mu \mathrm{g}$ protein, total INS lysates) were used to confirm similar levels of exocytotic protein components (b). (c, d) Quantification of immunoprecipitated and co-immunoprecipitated proteins was performed by normalising the immunoprecipitated protein band intensity to corresponding input protein band intensity (c), and input control expressed as \% of maximum density taking the most intense band in the blot as $100 \%$ (d). Light grey bar, $0.8 \mathrm{mmol} / 1$ glucose; dark grey bar, $16.7 \mathrm{mmol} / 1$ glucose plus $10 \mathrm{nmol} / 1$ GLP-1. Data represent means \pm SDs; ${ }^{*} p<0.05$. (e, f) Syn-4 interacts directly with VAMP2 (e) and VAMP8 (f). Syn-4 was co-expressed with VAMP2-GFP or VAMP8-mCherry in HEK293 cells by sequential transfection of pcDNA3.1-Syn-4 followed by adenovirus (Ad)-VAMP2-GFP or Ad-VAMP8-mCherry infection and immunoprecipitated with Syn-4 antibody. (g) Densitometric analysis of IP and input control expressed as ratio of VAMP to Syn-4. Results shown are representative of three independent experiments. Values represent means \pm SDs

VAMP2. This was confirmed in HEK cells co-expressing Syn-4 with VAMP2 or VAMP8: Syn-4 antibody immunoprecipitation of Syn-4 co-precipitated similar amounts of VAMP2 (Fig. 7e) and VAMP8 (Fig. 7f), as determined by densitometric analysis (Fig. $7 \mathrm{~g}$ ), suggesting that Munc18c-Syn-4 SNARE complexes include not only VAMP2 [14] but also
VAMP8. Since VAMP8 mediates recruitment and fusion of newcomer SGs [17], it is likely that the ability of Syn-4 to influence exocytosis of newcomer SGs can, at least in part, be attributed to interactions with VAMP8. Although SNAP23 is also co-precipitated with these SM-SNARE complexes, the precise role of SNAP23 in insulin exocytosis is unclear.

\section{Discussion}

In this study, we have elucidated the SG pools on which Syn-4 acts in human beta cells to mediate GSIS. Depletion of endogenous Syn-4 employing lenti-shRNA-RFP in human pancreatic islets (Fig. 1) inhibited GSIS in both first and second phases (Fig. 2), which is related to severe reduction in the RRP and mobilisation from the reserve pool (Fig. 3). TIRF M illustrated that Syn-4-KD inhibited pre-docked SG exocytosis with high- $\mathrm{K}^{+}$stimulation (Fig. 4). Syn-4-KD inhibition of first-phase GSIS was attributed to reduction in exocytosis of both pre-docked and newcomer (no-dock) SGs and secondphase GSIS inhibition was attributed to reduction in exocytosis of no-docked newcomer SGs (Fig. 5). Thus, Syn-4 regulates exocytosis of both pre-docked and newcomer SG pools underlying biphasic GSIS in human islet beta cells.

Distinct SM-SNARE complexes and regulators confer distinct exocytosis [5]. Munc18a activates to prime Syn-1A to form the SNARE complex (with SNAP25 and VAMP2) that mediates docking and fusion of SGs with the PM [1,2]. These pre-docked SGs sit on the PM for a long time until $\mathrm{Ca}^{2+}$ release is evoked to trigger exocytosis, accounting for firstphase GSIS $[1,2,20]$. When pre-docked SGs sit on the PM too long, some lose exocytosis competence; this has been blamed on an undefined 'ageing' process [28]. This defect is believed to be accentuated in pancreatic islet beta cells in type 2 diabetes. We had alternatively postulated that reduced levels of the SM-SNARE complex comprised of Munc18a, Syn-1A, SNAP25 and VAMP2 in beta cells contributed to the defective exocytosis of pre-docked insulin SGs in islets of individuals with type 2 diabetes $[29,30]$. More recent work showed that newcomer SGs contributed to primary exocytosis [4, 5, 23], and in fact far exceeded pre-docked SGs in the overall GSIS [5]. Remarkably, these newcomer SGs are recruited to the PM to undergo exocytosis with minimal to no residence time on the PM $[4,5]$. We had identified the exocytotic machinery mediating newcomer SGs [10, 16-19]-a second SMSNARE complex comprised of Munc18b, Syn-3, VAMP8 and SNAP25. In that body of work, we showed that depletion of endogenous Syn-3 [10] or VAMP8 [17] reduced newcomer SGs and that when exogenously expressed they restored the deficient newcomer SGs without affecting pre-docked SGs.

The structure-function interaction of Munc18c and Syn-4 and how this promotes SNARE complex formation with VAMP2 and SNAP25 is unravelling [31]. Interestingly, the 
recent report by Thurmond's group showed that Syn-4 levels were also reduced in islets of individuals with type 2 diabetes [15], suggesting that reduced Syn-4-SNARE complexes could be contributing to reduced biphasic GSIS in type 2 diabetes. Since Syn-4-mediated exocytosis of both predocked and newcomer SGs underlies the role of Syn-4 in biphasic GSIS, we wondered whether Syn-4-Munc18c complexes, known to bind VAMP2 [14], might also bind VAMP8; the latter might account for some of the reduction in newcomer SGs when Syn-4 was depleted. Indeed, Syn-4 co-immunoprecipitation of stimulated INS-1 brought down both VAMP2 and VAMP8, although VAMP2 was predominant (Fig. 7). Maximal stimulation co-precipitated more VAMP2 but not VAMP8; this suggests that Syn-4-mediated exocytosis of newcomer SGs might not be entirely attributed to its complex formation with VAMP8. Further studies are required to explore other as yet undefined mechanisms by which Syn-4 mediates the recruitment and exocytosis of newcomer SGs. Taken together, our results raise the possibility that fusion machinery induced by Munc18c-Syn-4 interactions might be redundant to Munc18a-Syn-1A in mediating exocytosis of pre-docked SGs [32], and to Munc18b-Syn-3 in mediating newcomer SGs [5]. This in turn suggests that restoring Syn-4 (and/or Munc18c) into islets in type 2 diabetes [15] might be a preferred strategy by which to rescue the deficient biphasic GSIS.

Funding This work was supported by grants to HYG from the Canadian Institute of Health Research (MOP 86544 and MOP 89889). Some of the equipment used in this study was supported by The 3D (Diet, Digestive Tract and Disease) Centre funded by the Canadian Foundation for Innovation and Ontario Research Fund, project number 19442.

Duality of interest The authors declare that there is no duality of interest associated with this manuscript.

Contribution statement All the authors contributed to the conception and design of the study, the acquisition, analysis and interpretation of data and drafting the article and revising it critically for important intellectual content. All authors approved the final version to be published. HYG is the guarantor of this work.

\section{References}

1. Sudhof TC, Rothman JE (2009) Membrane fusion: grappling with SNARE and SM proteins. Science 323:474-477

2. Burgoyne RD, Barclay JW, Ciufo LF, Graham ME, Handley MT, Morgan A (2009) The functions of Munc18-1 in regulated exocytosis. Ann N Y Acad Sci 1152:76-86

3. Kasai K, Fujita T, Gomi H, Izumi T (2008) Docking is not a prerequisite but a temporal constraint for fusion of secretory granules. Traffic 9:1191-1203

4. Shibasaki T, Takahashi H, Miki T et al (2007) Essential role of Epac2/ Rap1 signaling in regulation of insulin granule dynamics by cAMP. Proc Natl Acad Sci U S A 104:19333-19338
5. Gaisano HY (2014) Here come the newcomer granules, better late than never. Trends Endocrinol Metab 945:1-8

6. Kwan EP, Gaisano HY (2005) Glucagon-like peptide 1 regulates sequential and compound exocytosis in pancreatic islet beta-cells. Diabetes 54:2734-2743

7. Hoppa MB, Jones E, Karanauskaite J et al (2012) Multivesicular exocytosis in rat pancreatic beta cells. Diabetologia 55:1001-1012

8. Wheeler MB, Sheu L, Ghai M et al (1996) Characterization of SNARE protein expression in beta-cell lines and pancreatic islets. Endocrinology 137:1340-1348

9. Ohara-Imaizumi M, Fujiwara T, Nakamichi Y et al (2007) Imaging analysis reveals mechanistic differences between first- and secondphase insulin exocytosis. J Cell Biol 177:695-705

10. Zhu D, Koo E, Kwan E et al (2013) Syntaxin-3 regulates newcomer insulin granule exocytosis and compound fusion in pancreatic beta cells. Diabetologia 56:359-369

11. Spurlin BA, Thurmond DC (2006) Syntaxin 4 facilitates biphasic glucose-stimulated insulin secretion from pancreatic beta-cells. Mol Endocrinol 20:183-193

12. Yang C, Coker KJ, Kim JK et al (2001) Syntaxin 4 heterozygous knockout mice develop muscle insulin resistance. J Clin Invest 107:1311-1318

13. Spurlin BA, Park SY, Nevins AK, Kim JK, Thurmond DC (2004) Syntaxin 4 transgenic mice exhibit enhanced insulin-mediated glucose uptake in skeletal muscle. Diabetes 53:2223-2231

14. Jewell JL, Oh E, Thurmond DC (2010) Exocytosis mechanisms underlying insulin release and glucose uptake: conserved roles for Munc18c and syntaxin 4. AJP Regul Integr Comp Physiol 298:R517-R531

15. Oh E, Stull ND, Mirmira RG, Thurmond DC (2014) Syntaxin 4 upregulation increases efficiency of insulin release in pancreatic islets from humans with and without type 2 diabetes mellitus. J Clin Endocrinol Metab 99:E866-E870

16. Lam $P$, Ohno M, Dolai $S$ et al (2013) Munc $18 b$ is a major mediator of insulin exocytosis in rat pancreatic $\beta$-cells. Diabetes 62:2416-2428

17. Zhu D, Zhang Y, Lam PP et al (2012) Dual role of VAMP8 in regulating insulin exocytosis and islet beta cell growth. Cell Metab $16: 238-249$

18. Xie L, Zhu D, Kang Y, Liang T, He Y, Gaisano HY (2013) Exocyst Sec5 regulates exocytosis of newcomer insulin granules underlying biphasic insulin secretion. PLoS ONE 8:e6756

19. Xie L, Zhu D, Gaisano HY (2012) Role of mammalian homologue of Caenorhabditis elegans unc-13-1 (Munc13-1) in the recruitment of newcomer insulin granules in both first and second phases of glucose-stimulated insulin secretion in mouse islets. Diabetologia 55:2693-2702

20. Rorsman P, Renstrom E (2003) Insulin granule dynamics in pancreatic beta cells. Diabetologia 46:1029-1045

21. Gillis KD, Mossner R, Neher E (1996) Protein kinase C enhances exocytosis from chromaffin cells by increasing the size of the readily releasable pool of secretory granules. Neuron 16:1209-1220

22. Braun M, Ramracheya R, Bengtsson M et al (2008) Voltage-gated ion channels in human pancreatic $\beta$-cells: electrophysiological characterization and role in insulin secretion. Diabetes 57:1618-1628

23. Yasuda T, Shibasaki T, Minami K et al (2010) Rim2alpha determines docking and priming states in insulin granule exocytosis. Cell Metab 12:117-129

24. Olofsson CS, Göpel SO, Barg S et al (2002) Fast insulin secretion reflects exocytosis of docked granules in mouse pancreatic B cells. Pflugers Arch 444:43-51

25. Gaisano HY, Lutz MP, Leser J et al (2001) Supramaximal cholecystokinin displaces Munc18c from the pancreatic acinar basal surface, redirecting apical exocytosis to the basal membrane. J Clin Invest 108:1597-1611

26. Cosen-Binker LI, Lam PP, Binker MG, Gaisano HY (2007) Alcoholinduced protein kinase Calpha phosphorylation of Munc18c in 
carbachol-stimulated acini causes basolateral exocytosis. Gastroenterology 132:1527-1545

27. Cosen-Binker LI, Binker MG, Wang CC, Hong W, Gaisano HY (2008) VAMP8 is the v-SNARE that mediates basolateral exocytosis in a mouse model of alcoholic pancreatitis. J Clin Invest $118: 2535-2551$

28. Duncan RR, Greaves J, Wiegand UK et al (2003) Functional and spatial segregation of secretory vesicle pools according to vesicle age. Nature 422:176-180

29. Ostenson CG, Gaisano HY, Sheu L, Tibell A, Bartfati T (2006) Impaired gene and protein expression of exocytotic SNARE complex proteins in pancreatic islets of type 2 diabetic patients. Diabetes $55: 435-440$
30. Gaisano HY, Ostenson CG, Sheu L, Wheeler MB, Efendic S (2002) Abnormal expression of pancreatic islet exocytotic soluble $\mathrm{N}$ ethylmaleimide-sensitive factor attachment protein receptors in Goto-Kakizaki rats is partially restored by phlorizin treatment and accentuated by high glucose treatment. Endocrinology $143: 4218-4226$

31. Latham CF, Lopez JA, Hu SH et al (2006) Molecular dissection of the Munc18c/syntaxin4 interaction: implications for regulation of membrane trafficking. Traffic 7:1408-1419

32. Oh E, Kalwat MA, Kim MJ, Verhage M, Thurmond DC (2012) Munc18-1 regulates first-phase insulin release by promoting granule docking to multiple syntaxin isoforms. J Biol Chem 287:2582125833 